\title{
On the Structure and Molt Controlling Function of the Y-Organ in the Prawn Penaeus indicus.
}

\author{
K. Vijayan, ${ }^{1}$ Sunilkumar Mohamed and Arvind D. Diwan ${ }^{2}$ \\ Central Marine Fisheries Research Institute, ICAR. \\ Dr. Salim Ali Road, Cochin-682031. Kerala, India
}

\begin{abstract}
The morphological and histological structure of the Y-organ of Penaeus indicus is described. The gland $1-2 \times 0.3 \mathrm{~mm}(\mathrm{LXW})$ is located in between the mandibular and posterior dorsoventral muscle at the junction of prebranchial and branchial chambers. Histochemical tests were performed to determine the chemical nature of the $Y$-organ cells. Significant changes in the size and tinctorial affinity of the $\mathrm{Y}$-organ cells were observed in relation to the molt cycle. $Y$-organectomy experiments revealed that the onset of premolt development was inhibited, suggesting the presence of molt inducing factor in the Y-organ.
\end{abstract}

Molting being the indirect version of growth, the study of endocrine systems that regulate molting is of increasing interest, especially among penaeid prawns of aquaculture interest. Gabe's (1953) classical light microscopic work recorded an organ homologous to the insect prothoracic gland that is responsible for the control of molting in more than 100 species of malacostracan crustaceans. However, only minimal anatomical and cytological details of the organ were described by Gabe (1953), leaving much confusion concerning the Y-organ's exact location and identification. Later the extirpation and reimplantation experiments of Echalier $(1955,1959)$ in Carcinus maenas substantiated Gabe's suggestion that the $Y$-organ was involved in molt control. Echalier's results were later confirmed by similar studies on other brachyurans (Passano and Jyssum 1963; Carlisle 1957), isopods (Maissiat 1970; Charmantier and Trilles 1977) and penaeids (Bourguet et al. 1977).

Preliminary cytochemical investigations of the organ in various crustaceans have been reported by Gabe (1956), Hoffman

\footnotetext{
1 Present address: Central Institute of Brackishwater Aquaculture, 141, Marshal's Road, Madras-600 008, India.

: Corresponding author.
}

(1967), Aoto et al. (1974) and Simione and Hoffman (1975). The earliest report in penaeids is that of Dall (1965) who described the $\mathrm{Y}$-organ as a ventral gland in Metapenaeus sp. Later Bourguet et al. (1977) reported the same results in Penaeus japonicus. The only work on molt related changes of the Y-organ in natantia is that of Aoto et al. (1974).

Though reliable morphological criteria exist for locating the $\mathrm{Y}$-organ at present (Spindler et al. 1980), there is no information on its histological variation and molt controlling function during the molt cycle of Indian penaeid prawns. The present paper deals with the structure of $Y$-organ and its molt controlling function in the penaeid prawn $P$. indicus.

\section{Materials and Methods}

Penaeus indicus in different molt stages and ranging in size from $80-130 \mathrm{~mm}$ TL were obtained from culture ponds in and around Cochin. The prawns were acclimated in plastic pools and were used for dissection as needed. Molt stages were identified using changes in setal morphology (Diwan and Usha 1985). The Y-organ along with the branchiostegite was removed from the region between the mandibular and posterior dorsoventral muscle of the prebranchial chamber and immediately fixed in 
Bouin's fluid. After dehydration through ethanol grades, it was processed for histological preparations.

Sections of 6-8 $\mu \mathrm{m}$ thickness were cut and stained with Harris hematoxylin and eosin and also with Mallory's triple stain. For correlating the changes in the $Y$-organ and the molt cycle, the organ was excised from three different molt staged animals, i.e., premolt, postmolt and intermolt, and processed for histological studies.

To understand the chemical nature of the secretory products of the Y-organ, histochemical tests were carried out to detect protein, lipid, carbohydrates, DNA, RNA and cholesterol using standard procedures described by Pearse (1968).

Y-organectomy was performed on immature adult prawns of intermolt stage (80$120 \mathrm{~mm} \mathrm{TL})$ to study its functional significance in relation to molt cycle. A total of 41 prawns were selected for the experiment, and the $Y$-organ was removed from 24 animals while the remaining 17 Sham operated prawns had a small piece of muscle tissue equivalent in size to $Y$-organ removed from the adjacent region. During the surgical procedures a continuous flow of seawater was maintained through the gills using a gill irrigation system. Surgical wounds were immediately sealed by electrocauterization. Both the experimental and control prawns were kept individually in floating plastic cages which were suspended in plastic pools ( 1 tonne) with recirculating seawater. During the experimental period prawns were fed mollusc and crustacean meat up to $15 \%$ of body weight. Molt stage developments of each prawn in the experimental and control groups were recorded daily. Prawns were kept under constant observation until each animal completed at least one molt cycle during the experimental period. Student $t$ test was employed to test the significance of the $Y$-organectomy.

\section{Results}

The location and structure of the $Y$-organ in $P$. indicus is described for the first time.

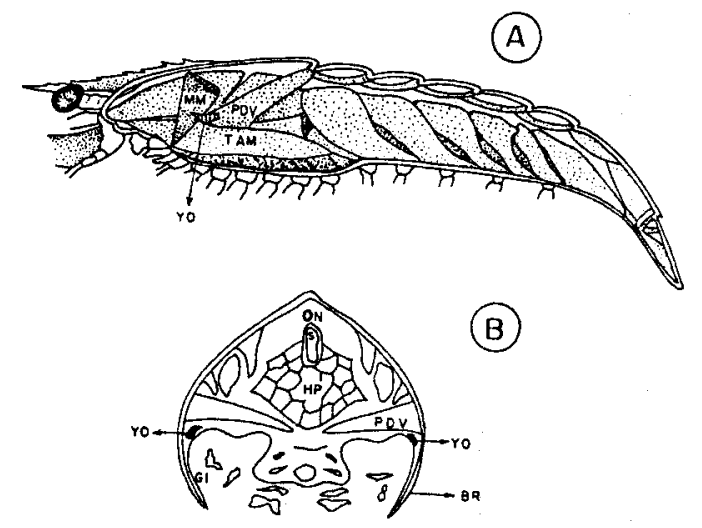

FIGURE 1. Schematic representation of the $Y$-organ in Penaeus indicus. Not to scale.

$1 A-$ Lateral view of the position of the $Y$-organ in relation to the adjoining muscles. MM-Mandibular Muscle, PDV - Posterior dorso-ventral muscle, TAMThoracicoabdominal Muscle and YO-Y-organ.

$1 B-$ Transverse section of the anterior cephalothorax through the level of Y-organ. S-Stomach, HP-Hepatopancreas, $P D V$-Posterior dorsoventral Muscle, $Y O-Y$-organ, GI-Gills, N-Nerve cord, and BRBranchiostegite.

The organ was observed as a narrow translucent strip of glandular tissue at the junction of prebranchial and branchial chambers (Figs. 1A, B). The anterior portion of the gland was adjacent to the mandibular muscle on an epidermal shelf and projected inwards from the inner wall of the branchiostegite. Posteriorly, the gland was found to be tapering and lay adjacent to the lateral end of the posterior dorsoventral muscle (Figs. 1A, B). In an adult animal, the size of the $Y$-organ varied from $1-2 \mathrm{~mm}$ in length and was $0.3 \mathrm{~mm}$ in width. The cuticular layer of the branchiostegite surrounding the $Y$-organ was seen to have extensive infoldings (Fig. 2). The inner cuticle of this region has an average thickness of $6 \mu \mathrm{m}$. The organ was separated from the surrounding blood sinus, muscle and connective tissue by a thin basal membrane. Minute capillaries and blood spaces were seen adjacent to the gland. No direct nerve supply to the $Y$-gland was evident.

Histologically, it was observed that the cells were closely packed and stained in- 


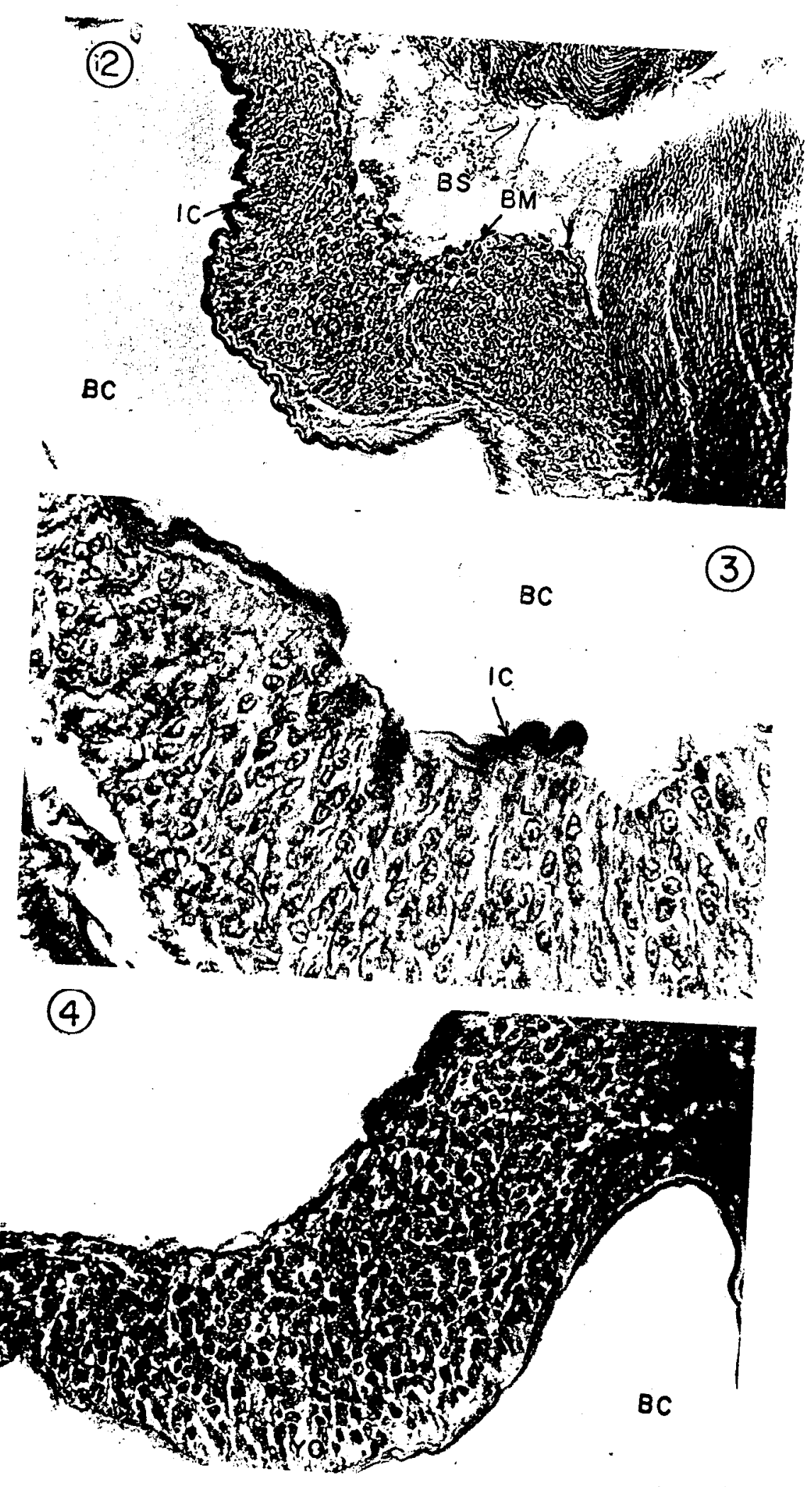


TABLE 1. Histochemical reactions of $Y$-organ in $P$. indicus.

\begin{tabular}{|c|c|c|c|c|c|c|}
\hline \multirow[b]{2}{*}{ Test applied } & \multicolumn{4}{|c|}{ Y-Organ cells } & \multirow[b]{2}{*}{$\begin{array}{l}\text { Inner } \\
\text { cuticle }\end{array}$} & \multirow[b]{2}{*}{ Inferences } \\
\hline & $\begin{array}{l}\text { Cytoplasmic } \\
\text { matrix }\end{array}$ & Nucleus & $\begin{array}{l}\text { Nuclear } \\
\text { wall }\end{array}$ & Nucleolus & & \\
\hline Mercuric Bromophenol Blue & + & ++ & ++ & ++ & + & $\begin{array}{l}\text { Presence of } \\
\text { general proteins }\end{array}$ \\
\hline Periodic acid Schiff (PAS) & - & - & - & - & ++ & $\begin{array}{l}\text { Absence of } \\
\text { glycogen }\end{array}$ \\
\hline Diastase digestion & - & - & - & - & - & \\
\hline Sudan Black B & - & - & - & - & + & Absence of lipid \\
\hline $\begin{array}{l}\text { Chloroform methanol } \\
\text { Cholesterol (Digitonin) }\end{array}$ & $\begin{array}{l}- \\
-\end{array}$ & - & - & - & - & $\begin{array}{l}\text { Absence of } \\
\text { cholesterol }\end{array}$ \\
\hline $\begin{array}{l}\text { Methyl green pyronin } \\
\text { Hot perchloric acid }\end{array}$ & $\begin{array}{l}++(\text { Pink }) \\
-\end{array}$ & $\begin{array}{l}+(\text { Pink }) \\
-\end{array}$ & - & $+($ Pink $)$ & - & Presence of RNA \\
\hline
\end{tabular}

tensely with hematoxylin indicating its basophilic nature. The whole gland was lobulated, each lobe having 7 to 12 cells with scarce cytoplasm, and cytoplasmic limits were hardly discernible (Fig. 3). The nuclei were oval to spherical in shape and measured $3-5 \mu \mathrm{m}$ in diameter. Nuclei were centrally or peripherally placed and chromatic granules were also seen. The cells were generally positive to protein with the nuclear wall showing intense staining with mercuric bromophenol blue. The PAS test gave a negative reaction, indicating the absence of carbohydrates. Sudan Black B and Digitonin test did not show any positive reaction. The Methyl green pyronin test indicated RNA positive reaction in the cytoplasm. The results of the histochemical tests are summarized in Table 1.

Histological and histochemical observations of the $\mathrm{Y}$-organ showed cyclic changes in size and staining properties of the cells in relation to molt cycle. In premolt stage, cells were larger in size $(8-9 \mu \mathrm{m})$ than that of postmolt and intermolt $(4-7 \mu \mathrm{m})$ stages. The cytoplasm was observed to increase in volume from early premolt stage (D0) to attain the maximum in late premolt stages D1 and D2-3 (Fig. 4). In the intermolt stage, cells showed normal cytoplasm but this was depleted in postmolt stage (Fig. 2). Cellular RNA content varied during the different stages of the molt cycle, with maximum staining intensity in premolt cells and minimal intensity in postmolt and intermolt cells. Y-organ cells stained deeply with hematoxylin in premolt stages, while affinity of the cells toward hematoxylin during the intermolt and postmolt stages was poor ( $\mathrm{Ta}$ ble 1).

Of the 24 animals in which bilateral Y-organ removal was carried out, 19 survived the experimental period and all the prawns failed to perform successful molts. Of the 19 prawns, seven showed an extended intermolt period of $148 \pm 48 \mathrm{~h}$ and died without entering the premolt. Four animals entered premolt and proceeded towards molting, but all of them failed to complete ecdysis successfully and died during exuviation. The remaining eight animals remained in premolt for a very long time, with

FIGLRE 2. Photomicrograph of the $Y$-organ of postmolt animal $(H \& E, \times 200)$. BC-branchial chamber; $B S-$

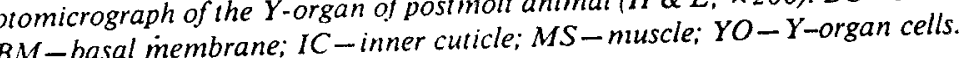

Figure 3. Y-organ of an intermolt animal $(H \& E, \times 400)$. L-Lobule.

FigURE 4. Y-organ of a premoll animal $(H \& E . \times 200)$. 
TABLE 2. Effect of $Y$-organectomy on molting process in P. indicus. ${ }^{\mathrm{a}}$

\begin{tabular}{lrc}
\hline \multicolumn{1}{c}{ Observations } & \multicolumn{1}{c}{$\begin{array}{c}\text { Intermolt } \\
\text { period } \\
(\mathrm{h})\end{array}$} \\
\hline No. of animals used for Y-organ & & \\
$\quad$ removal & 24 & \\
Animals survived after operation & 19 & \\
Animals died in intermolt & 7 & $148 \pm 48$ \\
Animals died in premolt period & 8 & $157 \pm 50$ \\
Animals died during molting & 4 & $153 \pm 42$ \\
No. of sham operated controls & 17 & \\
No. of controls molted & 17 & $42 \pm 8$ \\
\hline
\end{tabular}

a (Student $t$ test $\times P=0.05$ ).

an intermolt period of $157 \pm 50 \mathrm{~h}$, and all of them died without molting. At the same time all the 17 prawns in the control group completed the normal molt cycle successfully with an intermolt period of $42 \pm 8 \mathrm{~h}$ (Table 2). Intermolt period of Y-organectomized prawn showed significant variation from that of sham operated control prawns $(P<0.05)$.

\section{Discussion}

The histomorphology of the $\mathrm{Y}$-organ or molting gland observed in the present study in $P$. indicus is identical to that described for Metapenaeus sp. (Dall 1965), Palaemon paucidens (Aoto et al. 1974) and P. japonicus (Bourguet et al. 1977). The histology of the $\mathrm{Y}$-organ in $P$. indicus showed that the gland is of epidermal origin which is typical of diecdysic crustaceans (Spindler et al. 1980).

Histochemical tests that were employed to know the chemical nature of the $\mathrm{Y}$-organ showed negative reaction for carbohydrates and lipids, but failed to show the steroid secretory nature of the $\mathrm{Y}$-organ cells, probably due to the inability of the test to detect the nanogram levels of ecdysterone reported to be present in the $\mathrm{Y}$-organ cells of crustaceans (Spindler et al. 1980). Furthermore, it has been confirmed morphologically that the $\mathrm{Y}$-organ does not have storage sites and that the ecdysterone synthesized is released and transported to the target sites (Spindler et al. 1980). However, Aoto et al. (1974) working on the freshwater prawn $P$. paucidens, reported the occurrence of minute granules in the cells of $Y$-organ that stain with Sudan Black B in all stages of the molt cycle, although the absence of glycogen granules or lipid droplets agrees with the present findings. High levels of RNA and strong cytoplasmic basophilia detected in the cells point towards the synthetic nature of the gland.

- The size and the tinctorial affinity of the $Y$-organ cells varied markedly during the molting cycle of $P$. indicus. The volume changes noted in cells might be due to the increase in cytoplasmic content of the cells during the premolt followed by a decrease in the postmolt. The strong affinity towards RNA and hematoxylin and enlarged cell volume observed during the premolt stages in the present study probably indicate the high synthetic activity of the organ during premolt, which would result in the secretion of molt accelerating material. Reduced affinity of the cells towards the RNA and hematoxylin and decreased cell volume during postmolt and intermolt indicate decreased secretion of molting factors. These observations suggest a secretory behavior of $\mathrm{Y}$-organ, which is active during premolt and passive during postmolt and intermolt. Similar conclusions were also drawn by Aoto et al. (1974) in P. paucidens.

The Y-organectomy experiments clearly showed controlling function of this organ in molt of $P$. indicus. Among the $Y$-organectomized prawns the onset of premolt development was inhibited, indicating the presence of molt inducing or accelerating factor in the organ. Similarly Y-organectomy performed by various workers like Bourguet et al. (1977) in penaeids, Massiat et al. (1970) in isopods, and Burghause (1975) in amphipods also showed that this organ governs the molt controlling function in these animals. However, in the present experiment some of the $Y$-organectomized prawns entered the premolt stage and ad- 
vanced towards ecdysis, although ecdysis did not take place. A possible explanation for the initiation of molting in such animals might be the incomplete removal of the organs. Complete separation of this organ from the surrounding tissue in $P$. indicus is more difficult than in Brachyura, where the $\mathrm{Y}$-organs are discrete and more readily discernible in the live animals. The secretion of molt accelerating material by fragments of $Y$-organ left in place may be sufficient to initiate premolt development, while the presence of a complete $Y$-gland is required for ecdysis.

\section{Acknowledgments}

The authors are grateful to Dr. P. S. B. P. James, Director, Central Marine Fisheries Research Institute, Cochin for providing facilities and encouragement. They are also grateful to the Indian Council of Agricultural Research, New Delhi for financial assistance during the period of work.

\section{Literature Cited}

Aoto, T., Y. Kamiguchi and S. Hisano. 1974. Histological and ultrastructural studies on the Y-organ and the mandibular organ of the fresh water prawn. Palaemon paucidens, with special reference to their relation with moulting cycle. Journal of Faculty of Science, Hokkaido University, Series VI, 19:295-308.

Bourguet, J. P., J. M. Fxbryat, J. P. Trilles and G. Vernet. 1977. The Y-organ of Penaeus japonicus (Bate 1881)(Crustacea, Decapoda, Natantia) identity and description. Comptes Rendus de l'Academie des Sciences, Paris 285 D:977-980.

Burghause, F. 1975. The Y-organ of Orconectes limosus, Malacostraca, Astacura. Zoomorphologie Tiere $80(1): 41-57$.

Carlisle, D. K. 1957. On the hormonal inhibition of moulting in decapod crustacea. II. The terminal anecdysis in crabs. Journal of Marine Biological Association, UK 36:291-307. :

Charmantier, G. and J.P. Trilles. 1977. Control endocrine des phenomenes de la mue per les organes
Y chez Sphaeroma serratum ${ }^{1-1}$. Comptes Rendus de l'Academie des Sciences, Paris 285:905-908.

Dall, W. 1965. Studies on the physiology of a shrimp, Metapenaeus sp. (Crustacea: Decapoda: Penaeidae) II: Endocrines and control of moulting. Australian Journal of Freshwater Research 16:1-12.

Diwan, A. D. and T. Usha. 1985. Characterization of moult stages of Penaeus indicus based on developing uropod setal and some closely allied structures. Indian Journal of Fisheries 32:275-279.

Echalier, G. 1955. Role of the Y-organ in the induction of the moult in Carcinus maenas L. (Crustacea, Decapoda). Fisheries Research Board of Canada Translation, Ser. No. 1792.

Echalier, G. 1959. The Y-organ and the control of growth and moulting in Carcinus maenas (L), Crustacea, Decapoda. Fisheries Research Board of Canada, Translation Ser. No. 1964.

Gabe, M. 1953. Sur L' existence, chez quelques Crustaces malacostraces, d'un progane comparable a la glanda de la mue des insects. Comptes Rendus de l'Academie des Sciences, Paris 237:1111-1113.

Gabe, M. 1956. Histologie comparee de la glande de mue (organe $Y$ ) des Crustaceas Malacostraces. Annales des Sciences naturelles Ser II Zoologie 18: 145-152.

Hoffman, D. L. 1967. The structure of lymphogenous tissue of a Caridean shrimp previously described by $\mathrm{Y}$-organ (moulting gland). Canadian Journal of Zoology 45:886-889.

Maissiat, J. 1970. Edule experimentale due role de 'Organe' daus le determinisme endocrine de la mu chez isopode oniscoide Porcellio dilatatus. Comptes Rendus de l'Academie des Sciences 27:2573-2574.

Passano, L. M. and S. Jyssum. 1963. The role of the $\mathrm{Y}$-organ in crab proecdysis and limb regeneration. Comparative Biochemistry Physiology 9:195-213.

Pearse, A. G. E. 1968. Histochemistry. Theoretical and applied, volume 1,3 rd edition. J. and A. Churchill Ltd.

Simione, F. B., Jr. and D. L. Hoffman. 1975. Some effects of eye stalk removal on the Y-organs of Cancer irroratus Say. Biological Bulletin 148:440447.

Spindler, K., R. Keller and J. D. O'Connor. 1980. The role of ecdysteroids in the crustacean moulting cycle. Pages 247-280 in J. A. Hoffman, editor. Progress in ecdysone research. Biomedical Press. Elsevier/North Holland. 